\title{
Plasma Xanthine Oxidase Activity and Lipid Hydroperoxide Levels in Preterm Infants
}

\author{
MEDARDO C. SUPNET, REMEDIOS DAVID-CU, AND FRANS J. WALTHER
}

Division of Neonatology, Department of Pediatrics, Martin Luther King Jr./Drew University

Medical Center and UCLA School of Medicine, Los Angeles, California 90059

\begin{abstract}
Ischemia-reperfusion injury may affect morbidity and mortality in preterm and asphyxiated term infants. Reoxygenation of hypoxic tissues leads to the formation of free oxygen radicals by xanthine oxidase that may induce lipid peroxidation, enzyme inhibition, and DNA strand breakage. We measured arterial cord blood samples from 36 healthy term infants for baseline values and arterial blood sampled at 1 and $4 \mathrm{~h}$ after birth from 45 preterm infants admitted for intensive care for serial estimates of plasma xanthine oxidase activity and lipid hydroperoxide levels. Mean \pm SEM plasma xanthine oxidase activity in cord blood of term infants was $2.3 \pm 0.4 \mathrm{mU} / \mathrm{mL}$ and lipid hydroperoxide levels were $2.6 \pm 0.3 \mathrm{nmol} / \mathrm{mL}$. Eighteen of the 45 preterm infants met the criteria defining poor outcome (poor outcome group) and had lower umbilical arterial $\mathrm{pH}$ and base excess than the 27 preterm infants in the control group. Mean plasma xanthine oxidase activity in-
\end{abstract}

ABSTRACT

creased from $2.7 \pm 0.4$ at $1 \mathrm{~h} \mathrm{to} 4.7 \pm 0.6 \mathrm{mU} / \mathrm{mL}$ at $4 \mathrm{~h}$ of age $(p<0.001)$ in the poor outcome group and decreased from $2.1 \pm 0.3$ to $1.1 \pm 0.2 \mathrm{mU} / \mathrm{mL}(p=0.004)$ in the control group. Lipid hydroperoxide levels in the poor outcome group increased from $2.8 \pm 0.6 \mathrm{nmol} / \mathrm{mL}$ at $1 \mathrm{~h}$ to 4.3 $\pm 0.6 \mathrm{nmol} / \mathrm{mL}$ at $4 \mathrm{~h}$ of age $(p<0.001)$ and decreased from $2.1 \pm 0.6$ to $1.6 \pm 0.2 \mathrm{nmol} / \mathrm{mL}(p=0.008)$ in the control group. At $4 \mathrm{~h}$ of age, xanthine oxidase activity and lipid hydroperoxide levels were significantly higher in the poor outcome group than in the controls $(p<0.001)$. We conclude that serial measurements of plasma xanthine oxidase activity and lipid hydroperoxide levels may identify critically ill preterm infants destined for major neonatal morbidity and mortality and may be clinically useful as an indicator of severity of acute perinatal hypoxia-ischemia. (Pediatr Res 36: 283-287, 1994)
Free oxygen radicals play a major role in ischemiareperfusion or hypoxia-reoxygenation injury (1-6). During ischemia or hypoxia, the continuing use of ATP is not balanced by production of ATP, leading to degradation of energy-rich phosphates from ATP to AMP and further to adenosine. Adenosine is able to leave the cell and will be further degraded to inosine and hypoxanthine. Normally, hypoxanthine is metabolized to xanthine and xanthine to urate by the enzyme xanthine dehydrogenase with the use of $\mathrm{NAD}^{+}$as cosubstrate. Ischemia induces the conversion of xanthine dehydrogenase to xanthine oxidase by proteolytic modification and oxidation of sulfhydryl groups (7). Xanthine oxidase is an important source of free oxygen radicals, especially superoxide anions (8), because it is able to use molecular oxygen instead of $\mathrm{NAD}^{+}$as electron acceptor in the two-step conversion of hypoxanthine to uric acid. This reaction mechanism has

Received June 21, 1993; accepted April 7, 1994.

Correspondence and reprint requests: Frans J. Walther, M.D., Ph.D., Department of Pediatrics, King/Drew Medical Center, 12021 S. Wilmington Ave., Los Angeles, CA 90059.

Supported by the Research Centers in Minority Institutions Program of the National Institutes of Health (Grant 2G12 RR 3026). been confirmed in both animal and human studies (9-12) and is probably the primary source of reactive oxygen species after reperfusion of ischemic tissues (13). Release of xanthine oxidase in sick newborns was first hypothesized by Saugstad et al. in 1984 (14). Recent studies have shown a high xanthine oxidase activity in the fetal liver and intestine throughout gestation that increases in the liver and decreases in the intestine with advancing gestation (15) and have demonstrated the presence of endogenous xanthine oxidase in normal newborn plasma (16). Hypoxanthine, the main substrate of xanthine oxidase, has been proposed as an important marker for perinatal asphyxia $(9,12,17,18)$. Hypoxanthine levels were found to be increased in the vitreous humor of preterm infants who died of severe asphyxia (19) and in cord plasma of infants who experienced perinatal asphyxia $(12,17)$, suggesting that reactive oxygen species are instrumental in the compromised outcome of newborn infants after an asphyxial insult.

The deleterious effects of free oxygen radicals are secondary to lipid peroxidation, enzyme inhibition, and DNA strand breakage (4). Of these processes, the measurement of products of lipid peroxidation has been widely 
used in biologic studies to identify the occurrence of oxidant injury (20).

Growing evidence suggests that free oxygen radicals play a significant role in the development of morbidity and mortality in preterm infants and that major conditions such as bronchopulmonary dysplasia, pulmonary hemorrhage, retinopathy of prematurity, and necrotizing enterocolitis may in part be attributable to oxidant injury (21). To substantiate this claim, we tested the hypothesis that preterm infants with a severely compromised early neonatal outcome have experienced oxidant injury. We assumed increased xanthine oxidase activity to be the primary source of free oxygen radicals and the presence of plasma lipid hydroperoxides to reflect tissue damage from oxidant injury.

\section{METHODS}

Study population. Arterial cord blood samples were collected from 36 healthy term infants and arterial blood samples at 1 and $4 \mathrm{~h}$ after birth from 45 preterm infants with a gestational age less than $32 \mathrm{wk}$ admitted to our neonatal intensive care unit. The records of the latter infants were periodically reviewed to identify "poor outcome," defined as the occurrence of any of the following: early neonatal death, pulmonary hemorrhage within the first week after birth, presence of neuropathology (intra/ periventricular hemorrhage grade III or IV, seizures) within the first week after birth, or necrotizing enterocolitis (positive abdominal $x$-ray or bowel perforation surgery) within the first $2 \mathrm{wk}$ after birth. The infants with 1- and 4-h measurements were divided into two groups based on their outcome, i.e. those who met the poor outcome criteria (poor outcome group) and those who did not (control group).

This study was approved by the Institutional Review Board and written parental informed consent was obtained before the collection of blood samples.

Methods. All reagents were obtained from Sigma Laboratories (St. Louis, MO), except for perchloric acid, which was obtained from Aldrich Laboratories (Milwaukee, WI), and the LPO determiner kit, which was obtained from Kamiya Biomedical (Thousand Oaks, CA).

One $\mathrm{mL}$ of arterial blood was collected in ice-cold EDTA tubes and mixed with $100 \mu \mathrm{L}$ of a solution containing $10 \mathrm{mM}$ EDTA, $10 \mathrm{mM}$ dithioerythritol, and 10 $\mathrm{mM}$ phenylmethyl-sulfonyl fluoride in phosphate buffer $(\mathrm{pH} 7.35)$ to prevent inactivation or conversion of xanthine dehydrogenase to xanthine oxidase in vitro. The samples were transported on ice and spun at $1500 \times g$ for $15 \mathrm{~min}$ at $4^{\circ} \mathrm{C}$ to separate the plasma from the red blood cells. The plasma was divided into two parts: one part was frozen at $-20^{\circ} \mathrm{C}$ for lipid hydroperoxide assay within $1 \mathrm{wk}$, and one part was immediately processed for xanthine oxidase activity.

Xanthine oxidase activity. The plasma samples were passed over a $10-\mathrm{mL}$ Sephadex G-25 column of $4^{\circ} \mathrm{C}$, preequilibrated with phosphate buffer with DTT, phenyl- methylsulfonyl fluoride, and EDTA to remove endogenous substrates and low molecular weight inhibitors before measuring xanthine oxidase activity (22). The cord blood samples were assayed for xanthine oxidase activity using both spectrophotometric monitoring of the conversion of hypoxanthine (100 $\mu \mathrm{M}$ in phosphate buffer) to urate at $295 \mathrm{~nm} \mathrm{(23)} \mathrm{(1} \mathrm{unit} \mathrm{of} \mathrm{xanthine} \mathrm{oxidase} \mathrm{forms} 1$ $\mu \mathrm{mol}$ of urate from hypoxanthine/min at $25^{\circ} \mathrm{C}, \mathrm{pH}$ 7.9) and the oxidation of the chromogen ABTS [2, 2'-azinobis-(3-ethylbenzthiazoline-6-sulfonate)] by hydrogen peroxide generated in the two-step oxidation of hypoxanthine to urate with oxygen as electron acceptor at $410 \mathrm{~nm}$ (24). Baseline values were obtained for each sample by incubating samples with substrates and allopurinol (50 $\mu \mathrm{M})$. The two methods had an excellent correlation $(r=$ $0.99, p<0.001$ ), and the ABTS technique was used exclusively for measurement of xanthine oxidase activity in the 1- and 4-h arterial samples collected from the 45 preterm infants. Specific xanthine oxidase activity was expressed as $\mathrm{mU} / \mathrm{mL}$ plasma.

Lipid hydroperoxide assay. Lipid hydroperoxide levels were measured using the observation (25) that Hb catalyzes the reaction of lipid hydroperoxides with the methylene blue derivative MCDP (10-N-methylcarbamoyl3,7-dimethylamino-10-H-phenothiazine), forming an equimolar concentration of methylene blue with maximum absorbance at $675 \mathrm{~nm}$ (LPO determiner kit, Kamiya Biomedical). Cumene hydroperoxide was used as external standard in the assay. Lipid hydroperoxide levels were expressed as $\mathrm{nmol} / \mathrm{mL}$ plasma.

Statistics. Results are presented as mean \pm SEM. The means of two groups were compared with the $t$ test, and paired $t$ tests were used to compare the means of repeated measures. The association between birth weight/ gestational age and both xanthine oxidase activity and lipid hydroperoxide levels was determined by multiple regression analysis. A $p$ value less than 0.05 indicated statistical significance.

\section{RESULTS}

Table 1 summarizes the characteristics of the 36 healthy term newborn infants studied for arterial cord plasma xanthine oxidase activity and lipid hydroperoxide levels. Their mean xanthine oxidase activity was $2.3 \pm$

Table 1. Characteristics of the 36 healthy term newborn infants studied for cord plasma xanthine oxidase activity and lipid hydroperoxide levels

\begin{tabular}{lcc}
\hline & Mean \pm SEM & Range \\
\hline Birth weight (g) & $3580 \pm 109$ & $2290-4500$ \\
Gestational age (wk) & $39.2 \pm 0.4$ & $37-42$ \\
Vaginal/cesarean section delivery* & $23 / 13$ & \\
Males/females* & $16 / 20$ & \\
5-min Apgar score $\dagger$ & 9 & 9 \\
Arterial umbilical pH & $7.28 \pm 0.01$ & $7.22-7.37$ \\
\hline
\end{tabular}

* Absolute values.

$\uparrow$ Median values. 
Table 2. Characteristics of the 45 preterm infants admitted for intense care in whom 1 - and 4-h plasma xanthine oxidase and lipid hydroperoxide levels were measured

\begin{tabular}{|c|c|c|c|}
\hline & $\begin{array}{l}\text { Poor outcome } \\
\text { group }(n=18)\end{array}$ & $\begin{array}{l}\text { Controls } \\
(n=27)\end{array}$ & $p$ \\
\hline Birth weight (g) & $930 \pm 42$ & $1054 \pm 32$ & 0.02 \\
\hline Gestational age (wk) & $27.3 \pm 0.4$ & $28.7 \pm 0.3$ & 0.009 \\
\hline 5 min Apgar score* & 7 & 9 & 0.003 \\
\hline Art umbilical pH & $7.22 \pm 0.02$ & $7.31 \pm 0.01$ & $<0.001$ \\
\hline Base excess & $-8.8 \pm 0.9$ & $-2.8 \pm 0.4$ & $<0.001$ \\
\hline $\mathrm{RDS} \dagger$ and mechanical ventilation $>48 \mathrm{~h}$ & 15 & 22 & NS \\
\hline Early neonatal death $\ddagger$ & 10 & 0 & $<0.001$ \\
\hline Pulmonary hemorrhage $<1$ wk after birth & 2 & 0 & 0.07 \\
\hline Neuropathology $<1$ wk after birth & 10 & 0 & $<0.001$ \\
\hline Necrotizing enterocolitis $<2 \mathrm{wk}$ after birth & 6 & 0 & 0.001 \\
\hline
\end{tabular}

* Apgar scores are presented as median values.

$\dagger$ RDS, respiratory distress syndrome.

$\ddagger$ Morbidity/mortality are presented as absolute numbers.

$0.4 \mathrm{mU} / \mathrm{mL}$ and lipid hydroperoxide levels were $2.6 \pm 0.3$ $\mathrm{nmol} / \mathrm{mL}$.

Table 2 describes the characteristics of the 45 preterm infants $<32$ wk gestational age who had xanthine oxidase activity and lipid hydroperoxide measurements at 1 and 4 $\mathrm{h}$ of age. Eighteen of them met the poor outcome criteria and 27 formed the control group. Infants with poor outcome had lower birth weights $(p=0.02)$, were less mature $(p=0.009)$, and had lower 5-min Apgar scores ( $p$ $=0.003)$ and arterial umbilical $\mathrm{pH}$ and base excess $(p<$ 0.001 ) than the control group.

Figure 1 provides a summary of the plasma xanthine oxidase activity at 1 and $4 \mathrm{~h}$ after birth in the 45 preterm newborn infants with serial measurements. At $1 \mathrm{~h}$ of age, the mean xanthine oxidase activity in the group with poor outcome $(2.7 \pm 0.4 \mathrm{mU} / \mathrm{mL})$ was similar to that in the control group $(2.1 \pm 0.3 \mathrm{mU} / \mathrm{mL})$. At $4 \mathrm{~h}$ of age, the mean xanthine oxidase activity was significantly lower in the control group $(1.1 \pm 0.2 \mathrm{mU} / \mathrm{mL})$ than in the group with poor outcome $(4.7 \pm 0.6 \mathrm{mU} / \mathrm{mL}, p<0.001)$. Paired

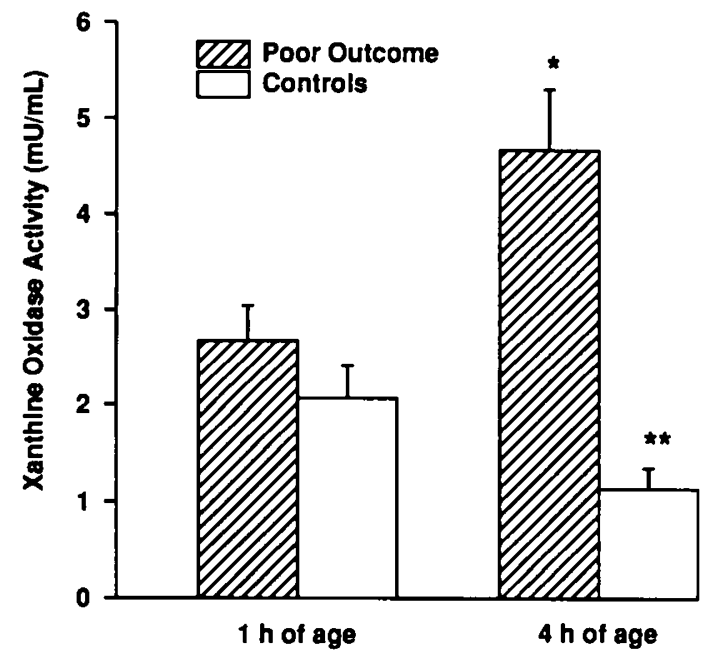

Figure 1. Mean \pm SEM plasma xanthine oxidase activity in newborn infants with poor outcome $(n=18)$ and control infants $(n=27)$ at 1 and $4 \mathrm{~h}$ after birth. ${ }^{*}, p<0.001 v s$ the 1 - and 4-h data of the control group and the 1-h data of the poor outcome group; ${ }^{* *}, p=0.004 \mathrm{vs}$ the 1-h data of the control group. analysis showed a significant decrease in the xanthine oxidase activity in the control group from 1 to $4 \mathrm{~h}$ after birth $(p=0.004)$, whereas the xanthine oxidase activity increased during this time period in the group with poor outcome $(p<0.001)$.

Plasma lipid hydroperoxide levels at 1 and $4 \mathrm{~h}$ after birth are shown in Figure 2. At $1 \mathrm{~h}$ of age, the mean lipid hydroperoxide level in the poor outcome group $(2.8 \pm 0.6$ $\mathrm{nmol} / \mathrm{mL})$ was similar to that in the control group $(2.1 \pm$ $0.3 \mathrm{nmol} / \mathrm{mL}$ ), but at $4 \mathrm{~h}$ of age the mean lipid hydroperoxide level was significantly lower in the control group $(1.6 \pm 0.2 \mathrm{nmol} / \mathrm{mL})$ than in the group with poor outcome $(4.3 \pm 0.6 \mathrm{nmol} / \mathrm{mL}, p<0.001)$. Paired analysis showed a significant decrease in the lipid hydroperoxide level in the control group from 1 to $4 \mathrm{~h}$ after birth $(p=0.008)$, whereas the lipid hydroperoxide level increased during this time period in the group with poor outcome $(p<$ $0.001)$.

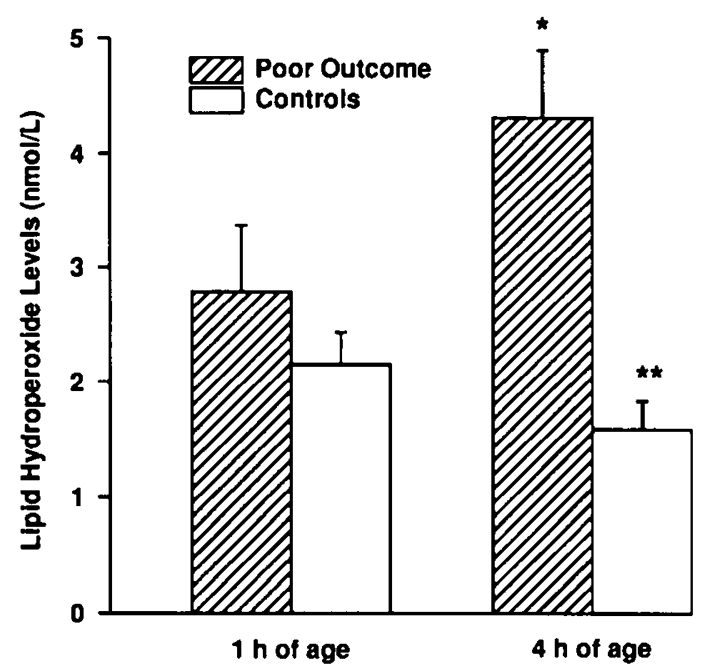

Figure 2. Mean \pm SEM plasma lipid hydroperoxide levels in newborn infants with poor outcome $(n=18)$ and control infants $(n=27)$ at 1 and $4 \mathrm{~h}$ after birth. ${ }^{*}, p<0.001$ vs the 1 - and 4 -h data of the control group and the 1 -h data of the poor outcome group; ${ }^{* *}, p=0.008$ is the 1-h data of the control group. 
Xanthine oxidase activity and lipid hydroperoxide levels were not dependent on birth weight and gestational age.

\section{DISCUSSION}

The question of whether oxidant injury plays a significant role in the development of poor outcome in newborn infants is of great clinical importance, especially when preventive measures are to be instituted. Fetal antioxidant activity in rodents and rabbits remains low until late gestation (26) and antioxidant activity in cord sera of infants with birth weights ranging from 830 to 3700 g correlates with birth weight (27), indicating that preterm infants may be deficient of antioxidants and at a higher risk for oxidant injury than term infants.

Xanthine oxidase plays a pivotal role in ischemiareperfusion injury (13). The production of free oxygen radicals by the hypoxanthine-xanthine oxidase system during reoxygenation after hypoxia may play a major role in the development of poor outcome in sick infants, as shown by elevated levels of hypoxanthine in the body fluids of preterm infants suffering or dying from severe respiratory distress syndrome $(12,19)$ with a positive correlation between hypoxanthine levels and the duration of hypoxia before death (19), in the plasma of infants who subsequently developed cavitating periventricular leukomalacia (28), and in some studies of cord blood of asphyxiated infants $(11,29)$. The latter finding was not corroborated by Lipp-Zwahlen et al. (30), who found a wide variation and overlap in the cord plasma hypoxanthine levels of normal infants and those with suspected intrauterine hypoxia. Plasma xanthine oxidase activity is relatively low under normal circumstances. In adult rats, plasma xanthine oxidase activity amounts to approximately $8-10 \mathrm{mU} / \mathrm{mL}(31,32)$, and in healthy adults activity ranges from 0 to $1.20 \mathrm{mU} / \mathrm{mL}(24)$. In adult patients, circulating xanthine oxidase activity is about $2 \mathrm{nmol} /$ $\mathrm{min} / \mathrm{mL}$ and increases to about $6 \mathrm{nmol} / \mathrm{min} / \mathrm{mL}$ after ischemic reperfusion (33). Tan et al. (16) found endogenous xanthine oxidase activity in plasma obtained at delivery from umbilical cord artery and vein to be $2.4 \pm$ 0.5 and $2.5 \pm 0.3$ (mean $\pm \mathrm{SD}) \mu \mathrm{U} / \mathrm{mL}$, consistently higher than in adult plasma (16). Our data on arterial cord plasma xanthine oxidase activity are similar to those of Tan et al. (16).

Between 1 and $4 \mathrm{~h}$ of age, xanthine oxidase activity decreased sharply in control infants, whereas it increased in infants with poor outcome. At $4 \mathrm{~h}$ of age, preterm infants who met the poor outcome criteria had significantly higher levels of plasma xanthine oxidase activity than preterm infants who did well. These results suggest that during the first hour after birth elevated levels of xanthine oxidase activity are a normal physiologic phenomenon, supporting the observation that hypoxanthine, the main substrate of xanthine oxidase, is elevated during the first $2 \mathrm{~h}$ after birth in about $50 \%$ of newborn infants regardless of their outcome (28). The changes in xanthine oxidase activity over time were accompanied by similar differences in lipid hydroperoxide levels. The pronounced increase in both parameters in the poor outcome group between 1 and $4 \mathrm{~h}$ of age suggests a role for oxidant injury in the subsequently emerging morbidity and mortality.

However, even though preterm infants with poor outcome have a higher plasma xanthine oxidase activity compared with those with good outcome, it has not been proven that any causality exists. Vettenranta and Raivio (15) showed in human fetuses that xanthine oxidase activity decreases in the intestine toward term. Therefore, there is a possibility that the higher xanthine oxidase activity in the poor outcome group, with a lower gestational age than the good outcome group, only reflects a higher xanthine oxidase activity in the intestine. Six infants of the poor outcome group suffered from necrotizing enterocolitis versus none in the controls, suggesting that necrotizing enterocolitis contributes to a higher xanthine oxidase activity in plasma, maybe even long before any symptoms of necrotizing enterocolitis appear.

The decision to perform 1- and 4-h measurements of xanthine oxidase activity and lipid hydroperoxide levels was based on the observation that free oxygen radical formation peaks at 2 min after reflow and continues up to $3 \mathrm{~h}$ of reperfusion (34). In adult transplant patients, lipid hydroperoxide levels peak $1 \mathrm{~h}$ after reperfusion of transplant organ tissues and return to baseline levels in $3-4 \mathrm{~h}$ (35). This was not the case in our population of preterm infants with a gestational age $<32$ wk. Pitkanen et al. (36) found that exhaled ethane and pentane levels, a measure of the degree of lipid peroxidation, are low during the first $24 \mathrm{~h}$ in very-low-birth-weight infants with severe respiratory distress syndrome but correlate positively with inspired oxygen concentrations after the third day of life, with a higher degree of peroxidation occurring in infants with poor outcome compared with those who survive intact. These data (36) suggest that peak lipid peroxidation occurs later than $4 \mathrm{~h}$ of age in preterm infants. However, these variations may also be explained by the methodologic differences in the various indices of lipid peroxidation measured.

From this study, we conclude that serial measurements of plasma xanthine oxidase activity and lipid hydroperoxides may distinguish critically ill infants destined for major morbidity and mortality. Plasma xanthine oxidase activity, and to a lesser extent plasma lipid hydroperoxide levels, at $4 \mathrm{~h}$ of age may be clinically useful as indicators of the severity of acute perinatal hypoxiaischemia in preterm infants.

\section{REFERENCES}

1. Kloner RA, Przyklenk K, Whittaker P 1989 Deleterious effects of oxygen radicals in ischemia/reperfusion. Circulation 80:1115-1127

2. Southorn PA, Powis G 1988 Free radicals in medicine. I. Chemical nature and biologic reactions. Mayo Clin Proc 63:381-389

3. Southorn PA, Powis G 1988 Free radicals in medicine: II. Involvement in human disease. Mayo Clin Proc 63:390-408

4. Ernster L 1988 Biochemistry of reoxygenation injury. Crit Care Med 16:947953 
5. Flaherty JT, Weisfeldt ML 1988 Reperfusion injury. Free Radical Biol Med 5:409-419

6. Cohen MV 1989 Free radicals in ischemia and reperfusion myocardial injury: is this the time for clinical trials? Ann Intern Med 111:918-931

7. Parks DA, Granger DN 1986 Xanthine oxidase: biochemistry, distribution and physiology. Acta Physiol Scand Suppl 548:87-99

8. McCord JM, Fridovich I 1968 The reduction of cytochrome $c$ by milk xanthine oxidase. J Biol Chem 243:5753-5760

9. Connors MC, Harkness RA, Simmonds RJ, Hytten FE 1981 The measurement of hypoxanthine, xanthine, inosine and uridine in umbilical cord and fetal blood samples as a measure of fetal asphyxia. Br J Obstet Gynaecol 88:381-390

10. Brown JM, Terada LS, Grosso MA, Whitmann DJ, Velasco SE, Patt A Harken AH, Repine JE 1988 Xanthine oxidase produces hydrogen peroxide which contributes to reperfusion injury of ischemic, isolated perfused rat heart. J Clin Invest 81:1297-1301

11. Ferreira R, Llesuy S, Milei J, Scordo D, Hourquebie H, Molteni L, de Palma C, Boveris A 1988 Assessment of myocardial oxidative stress in patients after myocardial revascularization. Am Heart J 115:307-312

12. Pietz J, Guttenberg N, Gluck L 1988 Hypoxanthine: marker for asphyxia. Obstet Gynecol 72:762-766

13. Saugstad OD, Aasen AO 1980 Plasma hypoxanthine concentrations in pigs. A prognostic aid in hypoxia. Eur Surg Res 12:123-129

14. Saugstad OD, Hallman M, Abraham JL, Epstein B, Cochrane C, Gluck L 1984 Hypoxanthine and oxygen induced lung injury: a possible basic mech anism of tissue damage? Pediatr Res 18:501-5(14

15. Vettenranta K, Raivio KO 1990 Xanthine oxidase during human fetal development. Pediatr Res 27:286-288

16. Tan S, Radi R, Gaudier F, Evans RA, Rivera A, Kirk KA, Parks DA 1993 Physiologic levels of uric acid inhibit xanthine oxidase in human plasma. Pediatr Res 34:303-307

17. Saugstad OD 1975 Hypoxanthine as a measurement of hypoxia. Pediatr Res 9:158-161

18. Saugstad OD 1988 Hypoxanthine as an indicator of hypoxia: its role in health and disease through free radical production. Pediatr Res 23:143-150

19. Saugstad OD, Rognum TO 1988 High postmortem levels of hypoxanthine in the vitreous humor of premature babies with respiratory distress syndrome. Pediatrics 81:395-398

20. Gutteridge JM, Halliwell B 1990 The measurement and mechanism of lipid peroxidation in biological systems. Trends Biochem Sci 15:129-135

21. Sullivan JL 1988 Iron, plasma antioxidants and the "oxygen radical disease of prematurity." Am J Dis Child 142:134l-1344
22. Schoutsen B, De Jong JW, Harmsen E, De Tombe PP, Achterberg DW 1983 Myocardial xanthine oxidase/dehydrogenase. Biochim Biophys Acta 762:519-524

23. Bergmeyer HU 1974 Xanthine oxidase. In: Bergmeyer HU (ed) Methods of Enzymatic Analysis, Vol 1. Academic Press, New York, pp 521-522

24. Majkic-Singh N, Bogavac L, Kalimanovska V, Jelic Z, Spasic S 1987 Spectrophotometric assay of xanthine oxidase with $2: 2^{\prime}$-azino-di(3-ethylbenzthidzoline-6-sulphonate) (ABTS) as chromogen. Clin Chim Acta 162:29-36

25. Ohishi N, Ohkawa H, Miike A, Tatano T, Yagi K 1985 A new assay method for lipid peroxides using a methylene blue derivative. Biochem Int 10:205-211

26. Frank L, Sosenko IRS 1987 Prenatal development of lung antioxidant enzymes in four species. J Pediatr 110:106-110

27. Sullivan JL, Newton RB 1988 Serum antioxidant activity in neonates. Arch Dis Child 63:748-757

28. Russel GAB, Jeffers G, Cooke RWI 1991 Plasma hypoxanthine: a marker for hypoxic-ischemic periventricular leucomalacia. Arch Dis Child 67:388-392

29. Ruth V, Fyhrquist F, Clemons G, Raivio KO 1988 Cord plasma vasopressin, erythropoietin, and hypoxanthine as indices of asphyxia at birth. Pediatr Res 24:490-494

30. Lipp-Zwahlen AE, Tuchschmid P, Silberschmidt M, Duc G 1983 Arterial cord blood hypoxanthine: a measure of intrauterine hypoxia? Biol Neonate 44:193202

31. Anderson BO, Moore EE, Moore FA, Leff JA, Terada LS, Marken AH, Repine JE 1991 Hypovolemic shock promotes neutrophil sequestration in lungs by a xanthine oxidase-related mechanism. J Appl Physiol 71:1862-1865

32. Terada LS, Dormish JJ, Shanley PF, Leff JA. Anderson BO, Repine JE 1992 Circulating xanthine oxidase mediates lung neutrophil sequestration after intestinal ischemia-reperfusion. Am J Physiol 263:L394-L401

33. Friedl HP, Smith DJ, Till GO, Thompson PD, Louis DS, Ward PA 1990 Ischemia reperfusion in humans; appearance of xanthine oxidase activity. Am J Pathol 136:491-495

34. Bolli R, Patel BS, Jeroudi MO, Lai EK, McCay PB 1988 Demonstration of free radical generation in "stunned" myocardium of intact dogs with the use of the spin trap $\alpha$-phenyl $\mathrm{N}$-tert-butyl nitrone. J Clin Invest 82:476-485

35. Rabl H, Khoschsorur G, Colombo T, Tatzber F, Esterbauer H 1992 Human plasma lipid hydroperoxide levels show a strong transient increase after successful revascularizations. Free Radical Biol Med 13:281-288

36. Pitkanen OM, Hallman M, Andersson SM 1990 Correlation of free oxygen radical-induced lipid peroxidation with outcome of very low birth weight infants. J Pediatr 116:760-764 